was infuriated by Darwin's counting him among creationists in the Origin, the error can be excused. Owen's wound was repaid in his anonymous review of the Origin, which opened an irreconcilable gulf between him and the Darwinites. The sixth and seventh essays cover the details of one stage in their revenge, the "hippocampus minor controversy" with Huxley over the relationship between man and apes. Huxley, who had been using Owen as a climbing frame for years, outclassed him as tactician and controversialist. The final essay covers minor topics (sea serpents, longevity, vivisection) used by Rupke to show how Owen sought to shift authority from the judiciary (in evidential standards), the clergy (in received wisdom) and the aristocracy (in inherited power) towards science, the real "ministry of truth", and how, once his ambition was achieved and he was installed in his cathedral in South Kensington, he was quite ready to argue against the patrons whom he had courted for so long.

Having spent the greater part of my life in the institution that Owen founded, and having read, used and admired substantial parts of his scientific work, I should be a ready convert to Rupke's "demythologising scholarship". My problem is Owen's prose. Rupke does not mention Owen's work on fishes, my own field. Here he is (in the 1860 textbook on palaeontology) summarizing the history of teleosts: "those species, such as the nutritious cod, the savoury herring, the rich-flavoured salmon, and the succulent turbot, have greatly predominated at the period immediately preceding and accompanying the advent of man; and that they have superseded species which, to judge by the bony Garpikes (Lepisosteus), were much less fitted to afford mankind a sapid and wholesome food". I have never found the prose or the ideas nutritious. Rupke also has trouble with Owen's style ("convoluted, evasive", "the fog of verbal obfuscation", "inimitable prose, resembling an obstacle course"). From the depth and range of his scholarship, Rupke has obviously spent years in Owen's company. Yet he has not come to like the man. At one point he paraphrases Hugh TrevorRoper on Edmund Backhouse: "the mere fact that Owen praised a colleague did not necessarily imply self-glorification". Owen would (anonymously) review his own books and write that he had been "favoured to listen" to his own lectures. I finished the book feeling no closer to understanding Owen the man; he remains an enigmatic giant. He was a great morphologist, but he was also a politician, and as H. L. Mencken put it, a good politician is as unthinkable as an honest burglar.

Colin Patterson is in the Department of Palaeontology, Natural History Museum, London SW7 5BD, UK.

\section{Logic and laws}

\section{Ziauddin Sardar}

The Rise of Early Modern Science: Islam, China and the West. By Toby E. Huff. Cambridge University Press: 1993. Pp. 409. £35, \$54.95.

Islamic Science and Engineering. By Donald Hill. Edinburgh University Press: 1994. Pp. 250. £39.95 (hbk); $£ 16.95$ (pbk).

QUESTIONS, the eleventh-century Muslim philosopher and scientist al-Baruni once said, have meaning only in the worldview and context within which they arise. The most often asked questions about the legacy of al-Baruni, Islamic science, is why it failed to produce a distinctively modern science. Similar questions have been raised about Chinese science. Joseph Needham, among others, has asked: "Given the superiority of Chinese science until the seventeenth century, why did China fail to produce a Galileo?"

Toby Huff sets out to answer these questions. From the eighth to the fourteenth centuries, he tells us, Islamic science was "the most advanced science in the world, greatly surpassing the West and China". Just what the achievements of Islamic science were is described by Donald Hill in his concise and masterly survey, which offers us a new synthesis based on recent research. The starting point for analysing the decline of Islamic science is the mathematical models of the fourteenth-century scientist ibn Shatir, and the work of astronomers at the famous observatory in Maragha, Adharbayjan, built in the thirteenth century by Nasir al-Din al-Tusi. According to Hill, the Maragha astronomers developed the Tusi couple and a theorem for the transformation of eccentric models into epicyclic ones. Copernicus not only used these two basic theorems to build his notion of heliocentricity but also used them at exactly the same points in the model. In other words, the lunar models of Copernicus and the Maragha school are identical. While Hill is concerned with discovering where Copernicus acquired the Maragha theory, Huff asks a much broader question. Why didn't ibn Shatir and his followers at Maragha take the leap to a heliocentric worldview? Why did the Muslims not go the last mile, especially when the Muslims had already taken on Ptolemy some two centuries earlier when ibn alHaytham had boldly declared that "the arrangements proposed for planetary motions in Ptolemy's Almagest were "false"'?

The answers, according to Huff, lie in the religious, sociological and cultural dimensions of the Muslim civilization. The blame rests squarely on Islamic law, Muslim family relationships, the universi- ty system and theological disputes. We are told that because Islamic law "does not recognise corporate personalities" and "the idea of personal liability and the concept of negligence are unknown to Islamic law", cities and universities and other legally autonomous entities could not evolve in the Muslim world. Various schools of legal thought insisted on maintaining their separate identities and principles and therefore aborted the development of universal legal principles. The "extremely personalised nature of human relations" and the dominance of "the traditional extended family" meant that the Muslim civilization was not able to formulate "generalised universal norms". Moreover, "Islamic occasionalism" denied that the laws of nature were governed by a rational order. Also, science was essentially a marginal activity in Muslim civilization: the brilliance of its scientists was an exception to the rule rather than the norm and, in any case, society did not support the scientists, as many of them presented a threat to Islamic theory.

Frankly, Huff's diagnosis is patent nonsense. Islamic law may not recognize "personal negligence" in the sense of European law, but it is based on a much broader notion of individual responsibility and accountability. It does recognize corporate personalities: the wuqfs, the pious trusts and foundations that provided funding for universities, were a type of autonomous corporation. The banality of the suggestion that Islamic occasionalism or any other Islamic 'ism' denies the existence of a rational order defies comprehension. One definition of a Muslim is someone who reflects on and ponders the rational order of the Universe. This is why one-third of all the verses in the Koran are devoted to praising reason and exhorting the believers to use reason. Moreover, it defies all logic, not to say evidence put forward by such scholars as A. I. Sabra, whose arguments are dismissed by Huff with a sleight of hand, to suggest that science was a marginal activity in Islam. Marginal activities are not patronized by caliphs and sultans or supported by a network of magnificent libraries or have scientists and scholars criss-crossing the globe hunting out manuscripts and visiting research institutions. And above all, marginal activities do not take a people to the zenith of civilization.

To substantiate his intangible thesis, Huff systematically presents a totally distorted picture of Islam. We are, for example, told that in Islamic law murder is treated as "a private matter in which the state does not interfere". This will come as news to a billion Muslims across the world. The area in which the "central authority maintains a continuous vigilance", we are told further, is that of "crimes against god, the hudud crimes". As a secondary-school Muslim kid will tell 
the Massachusetts sociologist, murder is a hudud crime. Islamic universities are dismissed as nonscientific institutions because, Huff alleges, contrary to much recent research, as charitable trusts they did not conduct research or hold examinations. But hospitals and observatories that were corporations, and according to Huff's own accounts, did conduct research and hold examinations, are given a primitive flavour and described as 'protoscientific'. So nothing that is not Western can be described as scientific! Many of Huff's arguments about Islamic law are based on discredited works by orientalists - some, such as that of Goldziher, more than a hundred years old.

So what were the reasons for the decline of Chinese science? Here, Huff points at the alleged irrationality and complexity of the Chinese language which is not conducive to "clear and unambiguous communication" and is therefore not suitable for scientific inquiry. There are two problems with this suggestion. First, it was the same Chinese language that led to the development of Chinese science in the first place and to the discovery of the magnetic needle, the rudder, gunpowder and other technologies that came in rather handy for the evolution of modern science in Europe. Second, it was the same language that enabled modern China to acquire nuclear technology and seems to be no hindrance to Japan, which uses a parallel system and clearly leads the world in many fields of scientific inquiry.

From the irrationality of Chinese language we move to the implausibility of Chinese metaphysics. The Chinese notions of the organic world of primary forces (yang and yin), Huff tells us, is hardly a metaphysics worthy of the name. It does assume that "there is a pattern to existence in all things and that there is a unique way (tao) for all things, but the explanation of the patterns of existence is not to be sought in a set of laws or mechanical processes, but in the structure of the organic unit of the whole". The whole notion is little more than "a primitive but natural instinct of mankind" and, at best, it yields meaningless binary oppositions such as light and darkness. There is a total absence in Chinese thought of "a genuine dialectic of disputation and a faith in reason". Funny, then, how the Chinese managed to build a whole civilization on this 'primitive', 'natural' notion and evolved a science without any idea of reason that, according to Needham, "was much more efficient than the occidental in applying human natural knowledge to practical human needs" and in many ways "was much more congruent with modern science than was the world outlook of Christendom".

Both China and Islam have an integrated worldview. In their unique and individual ways, these cultures do not place reason and ethics in two separate compartments. Although Islam extols the virtues of reason, it also warns against instrumental rationality - the intense debate in Muslim civilization between theologians and philosophers was a debate not about the use of reason but about the transformation of reason into an instrument of oppression. Both civilizations have a deep respect for nature: in Islam it is a sacred trust; in Chinese metaphysics it is an autonomous, integrated web; in both cases one approaches nature with respect and humility. Given the ecological devastation caused by modern science, both approaches have something going for them. And neither civilization accepts a totally mechanical view of the Universe. With hindsight, and a backhanded compliment to quantum physics, both can be said to be 'right'.

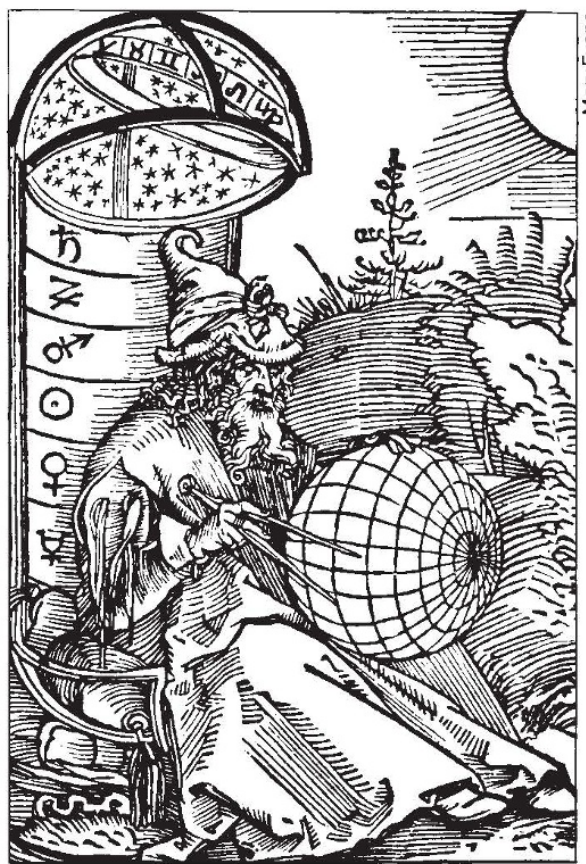

Mediaeval Arabic astronomer by Dürer.

What Huff is really saying is that modern science did not develop in Islam and China because these civilizations failed to produce mercantile capitalism and large corporations, and refused to accept a deterministic model of the Universe and treat nature as an empire to be, as Bacon put it, "tortured" so that its secrets can be extracted. We are presented with a distinctively right-wing capitalist view of history that, while acknowledging the achievements of Islamic and Chinese science, tries to expunge them from the history of modern science. Huff's goal is to preserve the purity of Europe by demonstrating that the origins of modern science lie not in China and Islam but in "the fusion of Greek philosophy, Roman law" and that most rational of all metaphysical systems, "Christian theology".

While the rise of modern science is presented by Huff as an exclusively European phenomenon, science itself is seen as bearing no cultural or social fingerprints of Europe. For a sociologist, Huff is dangerously unaware of recent advances in sociology of knowledge or the anthropology of science, and unfamiliar with the works of such philosophers of science as Paul Feyerabend, Imre Lakatos and Jerry Ravetz. Anything in Needham that does not fit his carefully constructed Eurocentric thesis is dismissed as inspired by Needham's Marxism. His notion of modern science as neutral, value-free, disinterested pursuit of uncontaminated truth is a pure fantasy.

Not surprisingly, the Europe of the Middle Ages that emerges from Huff's analysis is a heaven of rationality where religion had willingly taken a back seat, reason and conscience had been discovered for the first time and science advanced unhindered by dogma, persecution or other social and cultural impediments. In the twelfth century, we are told, Christianity in Europe had turned into a "corporation", a legal entity that did not really interfere with the work of the scientists - but, critics may ask, did it stop the emergence of the Inquisition a few centuries later? The "cultural outlook, social organization and economic performance" as well as "institutionalised disinterestedness and skepticism" of Europe prepared the ground for the emergence of modern science. The universities, far from being reluctant partners in scientific endeavour as is normally accepted, Huff contends, became the founding institutions of modern science. By the fifteenth century, the search for truth had become "part of the credo, the ethos, the cultural outlook of Europe". Of course, it was the same credo that launched Europe on its imperial adventure and colonization of the rest of the world. There is not even an iota of awareness in Huff's book that Europe is engaged in two conquests, that of nature and that of other cultures, at the same time. Nor is there an awareness that many postcolonial scholars, such as P. Petitjean and R. K. Kochhnar, have demonstrated an intimate connection between the origins of modern science and the emergence of the European Empire. Universality of modern science is established as an empirical consequence of European expansion, not an epistemological cause of valid claims.

While Islamic Science and Engineering consolidates the recent advances in the history of Islamic science and technology, The Rise of Early Modern Science provides us with an excellent example of the emerging new strain of deep Eurocentrism. Huff is concerned not only with showing that modern science is its own origins, final end and self-perpetuating force, but also insists that non-Western cultures have no future unless students 
from developing countries populate Western universities. (What they study in their own countries, in India, China and the Muslim world, tinged as it often is with their paranoid extended family systems and irrational metaphysics, can hardly be described as science!) Huff probably does not know that the Dogon people of West Africa, considered by anthropologists and orientalists to be one of the most primitive and irrational, knew many of the observations that Galileo's telescope made possible more than 1,500 years earlier. Two interesting questions arise. Did the Dogon invent some sort of telescope? Or did they have extraordinary eyesight?

Ziauddin Sardar is a consulting editor of Futures, a monthly journal of forecasting, planning and policy.

\section{Hypnosis revisited}

\section{H. J. Eysenck}

From Mesmer to Freud: Magnetic Sleep and the Roots of Psychological Healing. By Adam Crabtree. Yale University Press: 1993. Pp. 413. $\$ 50, £ 30$.

CrabTree is on the faculty of the Center for Training in Psychotherapy in Toronto, Canada, and a psychotherapist in a private practice. He is concerned to trace the historical roots of the practice of psychotherapy from Mesmer to Freud, and his historical knowledge is considerable; he cannot be faulted on the factual account he gives of Mesmer and his disciples, critics and followers. I had to look at the same literature when I was experimenting with hypnosis and suggestibility, and found it both fascinating and amusing. Through it all runs the Cartesian dilemma: if body and mind are separate entities, how can the mind influence the body? How can purely verbal manipulation of the mind (suggestion), as for instance in hypnosis, cause warts to disappear, breasts to grow larger, major surgery to be carried out without any feeling of pain? The answer of course is that Descartes was wrong; just as physicists had to learn to deal with a space-time continuum, so we will have to learn to deal with a bodymind continuum. But it took some time to appreciate this, and the history of how the role of suggestion was camouflaged as the effect of 'magnetic fluids' is long.

The famous Benjamin Franklin Commission in Paris, which was convened to judge Mesmer's claims on a scientific basis, hit the nail on the head. There were clear-cut cases of apparently miraculous cures of bodily ailments, but magnetic fluids had nothing to do with them; 'imagination' (suggestibility) was the important ingredient. The patients who were cured of a wide variety of often severely incapacitating diseases were very probably suffering from hysterical symptoms rather than physical ailments; these gross symptoms (hysterical blindness, lameness and so on) were fairly common before the First World War; they seem to have died out, and are hardly ever seen today. Of course, there were never any control groups, and there was little follow-up; neither was there any attention to failures, which were probably numerous. We cannot take the case histories as true accounts, either; quite likely they have grown in the telling. Even Freud's later case histories are known to have been economical with the truth; his fabled 'cures', as in the case of the Wolf Man, were not cures at all. The Wolf Man, after Freud's 'cure', continued for 60 years to show the same symptoms as before, despite much further therapy.

Crabtree tells the story well as it unrolls through names famous in the history of hypnosis, such as Puységur, Charcot, Binet, Braid and many others. They all made their contributions and discovered the main phenomena in this field. The Franklin Commission had already noted that a close bond seemed to develop between the magnetizer and the magnetized - shades of Freud's notions of 'transference'. Puységur used to interpret the dreams of his patients, and found their own interpretation useful. Many critics noted the tendency of young women (who probably constituted the majority of patients) to develop sexual affinities with their therapists, and such spiritual affinities do not always seem to have remained spiritual. Here again there are close parallels nearer home; many psychotherapists today seem to regard their profession as giving them a kind of droit de seigneur over attractive female patients; there are many cases coming up before ethical committees, or even judges. Plus ça change .... Finally, Mesmer brooked no disagreement among his followers and, like Freud, forced the leading spirits among them to split off and found their own movements. Truly history repeating itself, the second time as farce.

In a book such as this one might have expected some discussion of our modern views about the astonishing phenomena encountered. Nothing of the kind. The historical account trickles on, but no explanation is attempted of the 'cures' reported or of the many other details so painstakingly uncovered. We may presume that most if not all of the phenomena involved concern placebo effects, but oddly enough the word does not appear in the index. This is a pity: placebo effects are so universal and so strong that a thorough discussion would have been invaluable. An example is a recent study of medical treatments of several serious physical conditions, all of which had been in use over several years but had then been abandoned because proof had been forthcoming that they had no physical effect. The study showed that in 70 per cent of all cases where these useless treatments had been used, the treatments had in fact had excellent or very good effects. Another recent report compared Valium with a placebo in the treatment of anxiety and found no difference. When we consider that medical treatment until the time of Pasteur probably did more harm than good, we may conclude that the prestige of medicine is largely built on placebo effects - and in many cases probably continues along similar lines.

If this is true of physical diseases, it seems likely to be even more true in psychiatric disorders. When I pointed out in 1952 that psychoanalytic treatment had not been shown to have better outcomes in cases of severe neurotic disorders than no treatment or placebo treatment, orthodoxy was up in arms. Yet only recently a meta-analysis of the latest 19 studies comparing psychoanalytic treatment with no treatment at all reported that in none of the studies was there any evidence that the neurotics treated with psychoanalysis were any better a year after treatment was finished than the controls who had no treatment at all. The whole history of psychotherapy from Mesmer to Freud is a long list of theoretical inventions, from magnetic fluids to Oedipus complexes, to usurp the position that really should go to the placebos. In another large-scale metaanalysis, none of the most widely used psychotherapies did significantly better than placebo treatments.

Perhaps Crabtree as a psychotherapist did not feel inclined to discuss such matters; psychotherapists are not usually too happy with such facts. But by not even mentioning placebo treatment, Crabtree leaves out the Prince from Hamlet's tragedy; he makes it impossible for himself to offer any kind of explanation for the odd and extraordinary events he recounts so well. It is difficult to guess what readers not versed in these matters will make of the account; when they find that spiritualism, table-turning and psychic research (of the pre-scientific era) are drawn into the cauldron of speculation, they may well feel that we have left science behind and that Franklin and his commission really should have the last word - 'imagination' is at the back of it all. The pity is that only recently has there been much interest in the scientific study of suggestibility (although Binet made a brave start at the beginning of this century) and that Crabtree has nothing to say on the subject. Two cheers for a good history, but none for a lack of science.

\section{H. J. Eysenck is in the Institute of Psychiat- ry, De Crespigny Park, Denmark Hill, Lon- don SE5 8AF, UK}

